\title{
Research on Horizontal Carbon Emission Compensation for Inter-provincial Energy Cooperation Projects
}

\author{
Miao Yang \\ Zhejiang University of Technology, Zhejiang, China, 310024
}

Keywords: cross-provincial energy cooperation, carbon emissions, carbon emission compensation, carbon compensation mechanism

\begin{abstract}
In recent years, due to the ecological quality requirements and environmental capacity constraints of the economically developed provinces in the southeastern coastal areas, the transformation of traditional energy cooperation methods into new energy cooperation modes has been promoted. In the process of inter-provincial energy cooperation, the target of cooperation shifts from primary energy to secondary energy, and the carbon emissions in the energy processing process are mainly left in the energy export province. Today, in the control of total energy consumption, carbon emission rights are closely related to regional development rights. Traditional horizontal ecological compensation has not covered compensation for carbon emissions. Research on this has far-reaching significance. This paper takes the carbon compensation framework and the carbon emissions generated in the energy cooperation as the research object, and discusses the carbon emissions generated by the energy export provinces and energy input provinces under different energy cooperation forms.
\end{abstract}

\section{Introduction}

Global warming and the greenhouse effect are serious challenges for humanity. In recent years, the global greenhouse effect has become more and more serious, and low-carbon environmental protection has become the goal that mankind is constantly pursuing. Therefore, the total carbon emission control has become the basic consensus of the international community. On the one hand, from the international perspective, the intergovernmental climate change specialization The committee has been committed to the global greenhouse effect solution, actively engaged in negotiations on climate conferences on carbon reduction, and has made outstanding contributions to the global greenhouse effect. Both developed and developing countries are actively fulfilling their responsibilities, adopting the clean development mechanism CDM project between developed and developing countries, the joint implementation mechanism between developed and developed countries, and the emission trading mechanism ${ }^{[1]}$. 


\section{Based on the cross-provincial energy cooperation project horizontal carbon compensation}

theory and its realistic basis

\subsection{Determination of the concept of carbon offset}

\subsubsection{Carbon Compensation}

Carbon offset is defined in the Oxford English Dictionary as follows: Carbon offset refers to people calculating the carbon dioxide emissions directly or indirectly produced by their daily activities, and calculating the economic cost of offsetting this carbon dioxide, and then paying the individual to the specialized enterprise. Or institutions, which use trees or other environmental protection projects to offset the corresponding, amount of carbon dioxide in the atmosphere, which is also a national environmental protection action. The PA S2060 Carbon Neutralization Commitment issued by the British Standards Institute (BSI) also believes that carbon neutrality refers to a state in which global greenhouse gas emissions reach zero net increase, as shown in Figure 1 below:

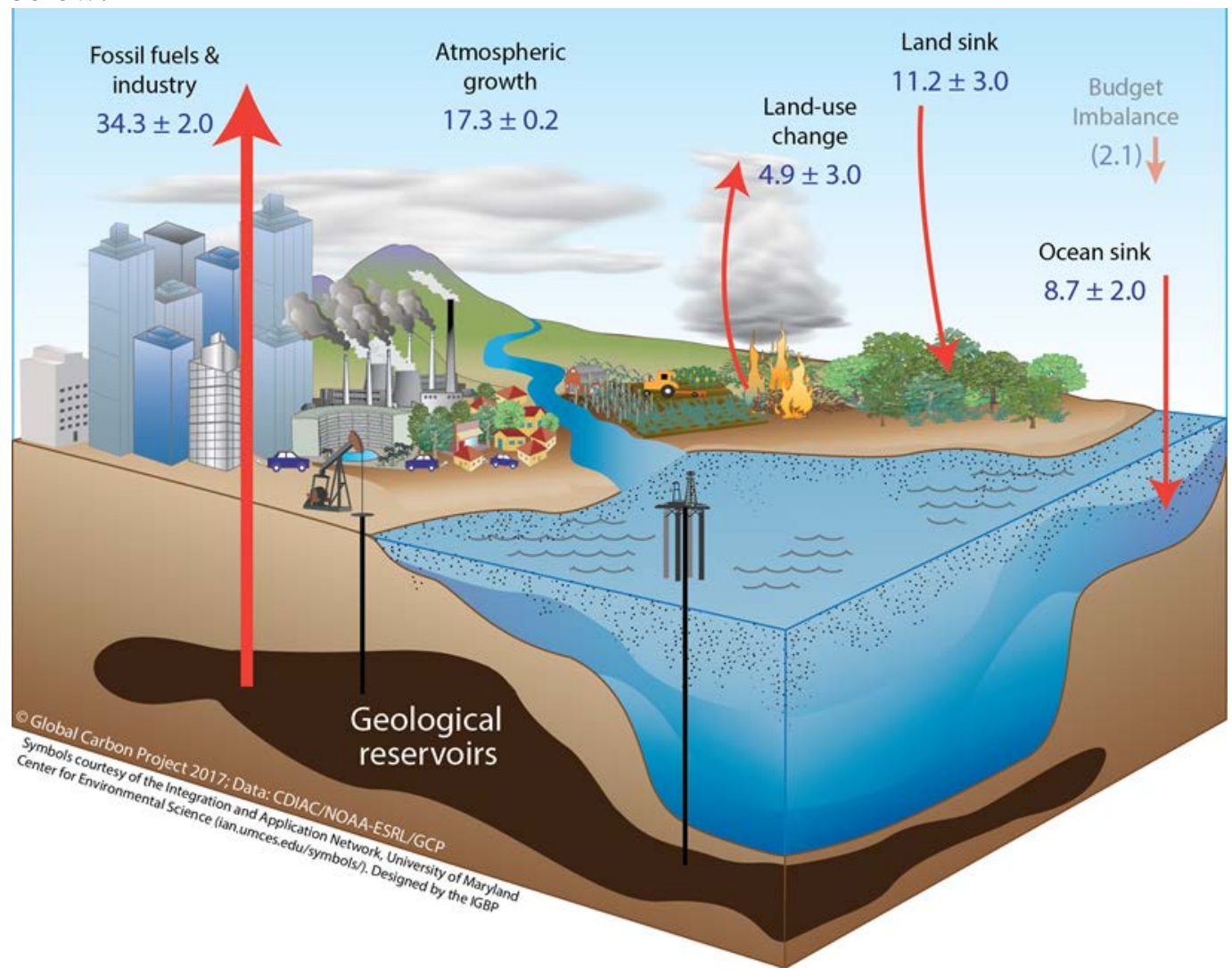

Figure 1 Global carbon emissions and compensation structure from 2007 to 2016

As shown in Figure 1 above, carbon offset is mainly based on the measurement of carbon emissions, through carbon emission reduction and carbon offset to achieve zero carbon emissions; Liu Huajie believes that the concept of carbon neutrality is greater than carbon compensation, carbon Compensation and carbon reduction. First of all, carbon emission reduction should be carried out by using renewable energy and improving efficiency ${ }^{[2]}$.

\subsubsection{Horizontal carbon compensation}

At present, although the academic community has made some research on horizontal ecological 
compensation, the academic research on horizontal carbon compensation is still in an almost blank state. Horizontal carbon compensation is a relatively new formulation; the form of horizontal fiscal transfer payment as shown in Figure 2 below is constructed:

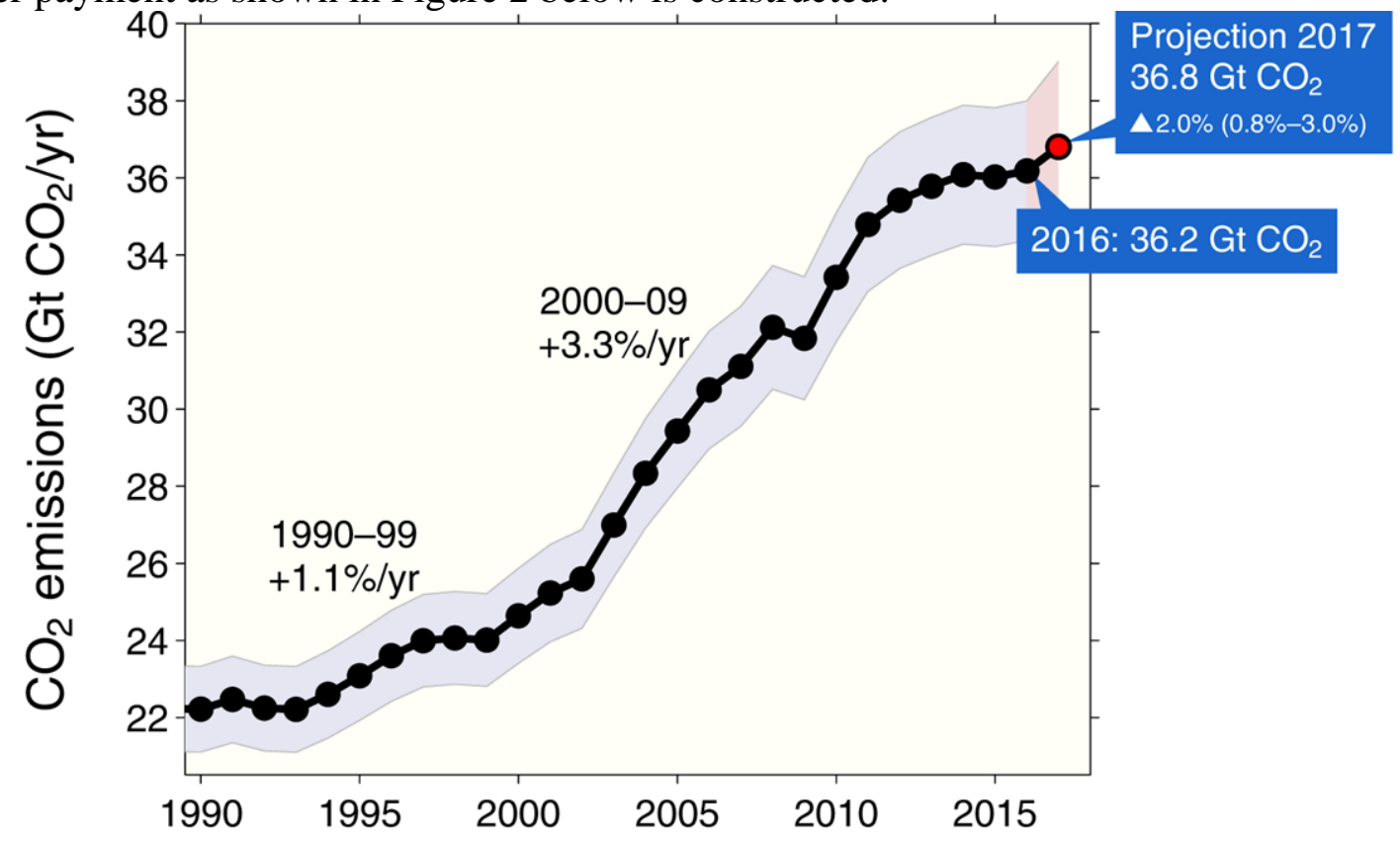

Figure 2 Data derivation of carbon compensation from a lateral angle

In addition to the statistical data derivation form of Figure 2 above, it can also be used in the form of horizontal development projects, so that energy consumption provinces can give certain compensation to energy production provinces through fund compensation, factor compensation, policy compensation, and carbon emission rights compensation. In order to complete the horizontal carbon offset between the provinces and achieves "carbon justice" between the two provinces ${ }^{[3]}$.

\subsection{Theoretical basis for horizontal carbon compensation based on cross-provincial energy cooperation projects}

\subsubsection{Public product theory}

In economics, products that satisfy both non-competitive and non-exclusive are called public goods. The so-called non-competitive means that more people do not need to increase the marginal cost, or the marginal cost is negligible. Therefore, if someone consumes a certain commodity, it does not prevent others from consuming the product at the same time. Non-exclusiveness refers to the inability to consume consumer behavior, or the high cost of charging, so that people can consume a certain commodity without paying the price. Public goods are offered to people at zero marginal cost, and no one is excluded from consumption ${ }^{[4]}$.

\subsubsection{Pig-out means and external compensation theory}

If a person or a company engages in economic activities to bring harm or benefits to other individuals or society, and they do not pay corresponding compensation, economics calls it externality, also known as externality theory. The impact of changes in carbon emissions is shown in Figure 3 below: 


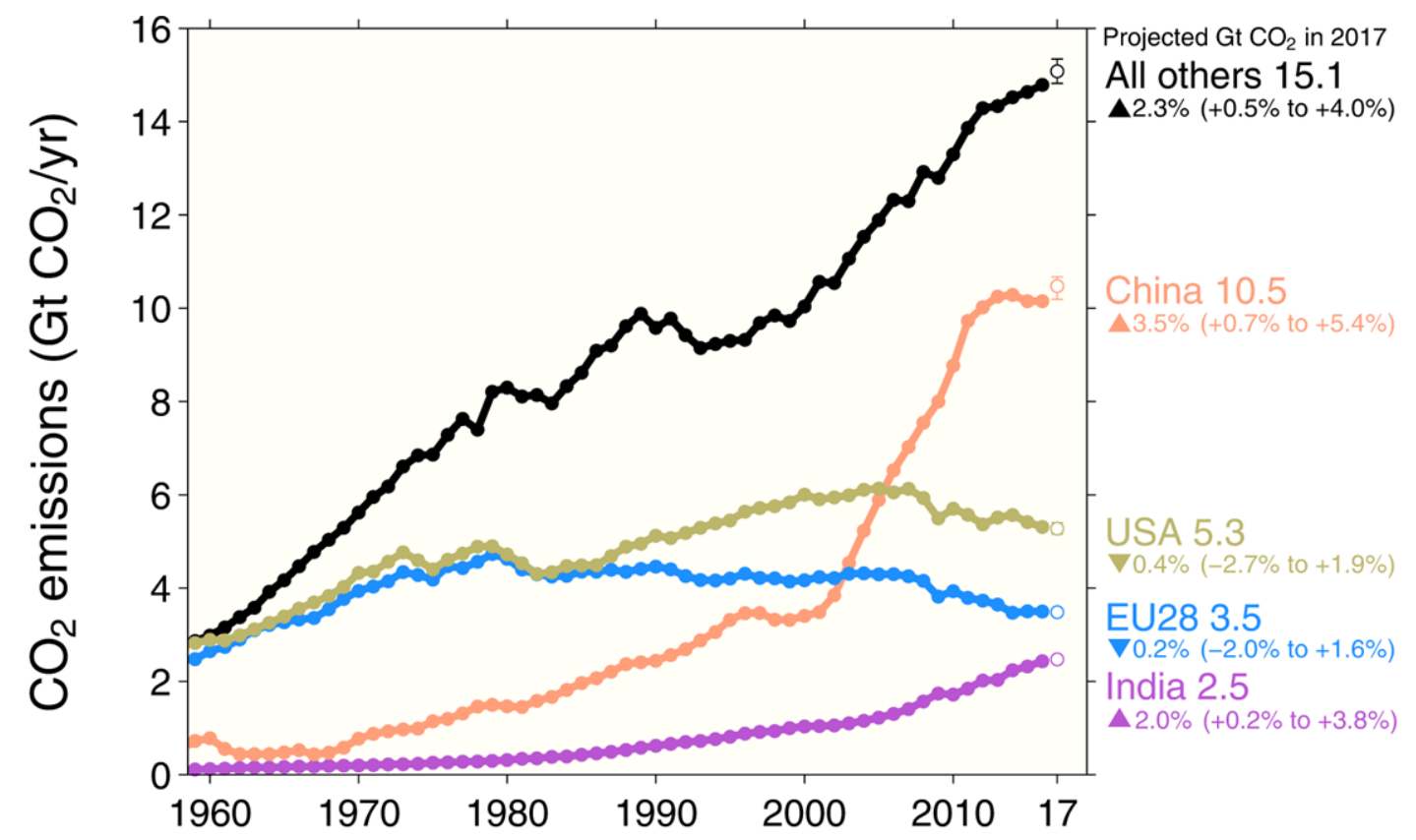

Figure 3 Legend of external compensation theory based on Pig-out means

As shown in Figure 3 above, externality refers to situations in which an individual or an enterprise does not have to fully bear its decision-making costs or is unable to fully enjoy its decision-making effectiveness, that is, the cost or benefit cannot be completely endogenous.

3. Cross-regional ecological compensation research at home and abroad and the dilemma faced by horizontal carbon compensation

\subsection{Analysis of cross-regional carbon emission compensation characteristics based on energy cooperation}

At present, there are two main types of inter-provincial energy cooperation in China. One is that the energy-input provinces plan to arrange coal-fired thermal power generation within the domain, and the other is to sign a thermal coal contract with the energy-rich provinces to protect the area. The economically developed provinces in the southeastern coastal areas have started to promote the transformation of inter-provincial energy cooperation modes from the "Eleventh Five-Year Plan". The characteristics of "migration" can effectively analyze the compensation characteristics of carbon emissions using the following data formula:

$\mathrm{CO}_{2}$ emissions from activities $=$ activity data $\times$ emission factors

Among them:

Heavy oil emission coefficient $=2.991 \mathrm{kgCO}_{2} / \mathrm{L}$

$\checkmark$ Diesel emission coefficient $=2.778 \mathrm{kgCO}_{2} / \mathrm{L}$

$\checkmark \mathrm{C} 2 \mathrm{H} 2$ emission coefficient $=3.3846 \mathrm{kgCO}_{2} / \mathrm{L}$

- Gasoline emission coefficient $=2.361 \mathrm{kgCO}_{2} / \mathrm{L}$

In the above formula, first of all, the joint construction of the coal-fired power plant can reduce coal transportation and reduce environmental pressure, but the energy export provinces leave the pollution of the coal-fired power plant production process. The second is too jointly build a coal-to-gas project, which refers to coal that is subjected to gasification and syngas, and then machinated to produce substitute natural gas ${ }^{[5]}$. 


\subsection{Challenges of inter-provincial horizontal carbon offsets in energy cooperation}

Foreign scholars have made in-depth research on cross-regional horizontal carbon compensation based on projects. Therefore, there are still many challenges in establishing a horizontal carbon compensation mechanism based on cross-provincial energy cooperation projects in China, mainly in the following aspects:

The law on horizontal compensation has not yet been formed

- Carbon offset lacks uniform standards

$\checkmark$ Less carbon source funding sources

\section{Conclusions}

In recent years, due to the ecological quality requirements and environmental capacity constraints of economically developed areas in the southeastern coastal areas, the transformation of inter-provincial energy cooperation modes has been promoted, and the provinces have changed from coal transportation to Jiankengkou coal-fired power plants and coal-to-gas projects. Thus, the "positive output" of clean energy sources and the "reverse migration" of emission sources are formed. Therefore, the horizontal carbon compensation in the process of cross-provincial energy cooperation has been paid attention to by the academic circles, and the accounting of carbon emissions in the process of cooperation and the allocation of emission rights quotas have also received attention.

\section{Acknowledgements}

Ministry of Education Project "Research on carbon Emission compensation of Trans-provincial Energy Cooperation Project" (item number: 14YJCZH109);

Zhejiang Province Social Science and Technology Federation Project $<$ Research on Transverse carbon compensation path in Trans-provincial Energy Cooperation Project (Project number: 2016N60Y)

\section{References}

[1] Tie J, Cao J, Wu M, et al. Compensation of Horizontal Gravity Disturbances for High Precision Inertial Navigation [J]. Sensors, 2018, 18(3):906-.

[2] Liu K, Li T, Li T, et al. Thermal behavior analysis of horizontal CNC lathe spindle and compensation for radial thermal drift error [J]. International Journal of Advanced Manufacturing Technology, 2018, 95(1-4):1293-1301.

[3] Hua Z, Fei L, Hofmann H, et al. A Six-Plate Capacitive Coupler to Reduce Electric Field Emission in Large Air-Gap Capacitive Power Transfer[J]. IEEE Transactions on Power Electronics, 2018, PP(99):1-1.

[4] Rassame S, Hibiki T. Drift-flux correlation for gas-liquid two-phase flow in a horizontal pipe[J]. International Journal of Heat \& Fluid Flow, 2018, 69:33-42.

[5] Zheng G, Lu W, Guo Y. Analysis on motion compensation for a horizontal stable platform[J]. Australian Journal of Mechanical Engineering, 2017:1-10. 